\title{
Capacitação Pedagógica nos Programas de Residência Multiprofissional em Saúde: Metodologia para Construção de Proposta
}

\author{
Pedagogical Training in Multiprofessional Health Residency Programs: Proposal-Building Metho- \\ dology
}

\section{Capacitación Pedagógica en los Programas de Residencia Multiprofesional en Salud: Métodos para Construcción de Propuesta}

Lais Mariano Paiva ${ }^{1}$, Cláudia Mara de Melo Tavares*

Como citar esse artigo. Paiva, LM; Tavares, CMM. Capacitação Pedagógica nos Programas de Residência Multiprofissional em Saúde: Metodologia para Construção de Proposta. Revista Pró-UniverSUS. 2019 Jan./Jul.; 10 (1): 150-153.

\section{Resumo}

A presente pesquisa apresenta a metodologia de construção de um módulo de curso de capacitação pedagógica no âmbito da residência multiprofissional em saúde, desenvolvido durante o Curso de Mestrado Profissional. O objetivo foi descrever a metodologia utilizada para desenvolver um produto destinado à capacitação pedagógica dos enfermeiros para atuar como preceptor em residência multiprofissional em saúde mental. Para analisar as necessidades concretas desta formação na residência valeu-se da pesquisa documental. O módulo de ensino proposto guiou-se pela perspectiva de aprendizagem significativa de Ausubel e foi delineado tomando-se por base situações-problemas vivenciados pelos próprios profissionais. O presente estudo traz contribuições para a elaboração de um módulo de ensino sobre capacitação pedagógica para atividade de preceptoria em saúde mental.

Palavras-chave: Curso de Capacitação; Residência e Internato; Saúde Mental.

\begin{abstract}
The present research presents the methodology of construction of a module of pedagogical training course within the scope of multiprofessional residency in health, developed during the Professional Master Course. The objective was to describe the methodology used to develop a product intended for the pedagogical training of nurses to act as a preceptor in multiprofessional residence in mental health. To analyze the concrete needs of this formation in the residence was worth of the documentary research. The proposed teaching module was guided by Ausubel's meaningful learning perspective and was outlined based on situations-problems experienced by the professionals themselves. The present study provides contributions for the elaboration of a teaching module on pedagogical training for preceptory activity in mental health.

Keywords: Training Courses; Internship and Residency; Mental Health.
\end{abstract}

\section{Resumen}

La presente investigación presenta la metodología de construcción de un módulo de curso de capacitación pedagógica en el ámbito de la residencia multiprofesional en salud, desarrollado durante el Curso de Maestría Profesional. El objetivo fue describir la metodología utilizada para desarrollar un producto destinado a la capacitación pedagógica de los enfermeros para actuar como preceptor en residencia multiprofesional en salud mental. Para analizar las necesidades concretas de esta formación en la residencia se valió de la investigación documental. El módulo de enseñanza propuesto se guió por la perspectiva de aprendizaje significativo de Ausubel y fue delineado tomando como base situaciones-problemas vivenciados por los propios profesionales. El presente estudio trae contribuciones para la elaboración de un módulo de enseñanza sobre capacitación pedagógica para actividad de preceptoria en salud mental.

Palabras clave: Cursos de Capacitación; Internado y Residencia; Salud Mental. 


\section{Introdução}

As residências multiprofissionais e em área profissional da saúde, criadas a partir da promulgação da Lei $\mathrm{n}^{\circ} 11.129$ de 2005, são orientadas pelos princípios e diretrizes do Sistema Único de Saúde (SUS), a partir das necessidades e realidades locais e regionais, e abrangem as profissões da área da saúde, a saber: Biomedicina, Ciências Biológicas, Educação Física, Enfermagem, Farmácia, Fisioterapia, Fonoaudiologia, Medicina Veterinária, Nutrição, Odontologia, Psicologia, Serviço Social e Terapia Ocupacional ${ }^{1}$.

A Residência é considerada uma modalidade de treinamento em serviço e se caracteriza pela aprendizagem da prática profissional através da aquisição de conhecimentos técnicos da profissão, habilidades e experiência, incluindo situações rotineiras, relações interpessoais, processos de gestão e fundamentos da profissão, tudo pela aquisição progressiva do conhecimento adquiridos no dia a dia do treinamento ${ }^{2}$.

A residência multiprofissional em saúde mental integra o conjunto de propostas de qualificação dos trabalhadores de saúde, promovida pelo Ministério da Saúde em conjunto com o Ministério da Educação, criadas a partir da promulgação da Lei $\mathrm{n}^{\circ} 11.129$ de 2005. Propõe uma formação que guarde íntima articulação entre teoria/prática, visando o compromisso com as necessidades de saúde das pessoas e com a consolidação do SUS. Tendo como principal objetivo desenvolver habilidades profissionais para atuação em equipe de forma interdisciplinar e ética paralelamente interagindo com a cultura da população assistida, além de promover uma reflexão histórico-crítica sobre a constituição do campo da psiquiatria e da saúde mental. Está orientada, atualmente, pelos princípios da Reforma Psiquiátrica, definida como um processo histórico de formulação crítica e prática, que tem como objetivos e estratégias o questionamento e elaboração de propostas de transformação do modelo clássico e do paradigma da psiquiatria ${ }^{3}$.

As atividades práticas desenvolvidas pelos residentes nos serviços de saúde são supervisionadas pelo preceptor, profissional vinculado à instituição formadora ou executora, com formação mínima de especialista, da mesma área profissional e que atua profissionalmente no cenário de prática ${ }^{4}$.

Contudo, os preceptores nem sempre se preocupam com a formação efetiva do residente. De acordo com os alunos residentes, a maioria dos preceptores desconhecem a amplitude de sue papel educativo na formação de novos profissionais, aqueles que reconhecem, conseguem desenvolver melhor suas atividades diárias, colaborando de forma mais efetiva no ato de ensinar, acolher, acompanhar, avaliar, construir e ressignificar os saberes. Nesse sentido, há necessidade de termos preceptores informados sobre seu papel, para que possam criar estratégias educativas adequadas durante o processo de supervisão-capacitação dos especialistas, favorecendo a aprendizagem e colaborando para a formação adequada de novos especialistas ${ }^{5}$.

Mas como os enfermeiros preceptores podem exercer seu papel pedagógico junto aos residentes se não receberam formação especifica para isso?

Diante desse contexto, delimitamos como problema de estudo a capacitação do enfermeiro no nível de especialista para atuar como preceptor em residência multiprofissional em saúde mental.

O objetivo do presente trabalho é descrever a metodologia utilizada para desenvolver um produto destinado à capacitação pedagógica dos enfermeiros para atuar como preceptor em residência multiprofissional em saúde mental. O produto foi desenvolvido durante a realização do Mestrado Profissional Ensino na Saúde.

\section{Metodologia de Desenvolvimento do Produto}

Com base na análise realizada dos programas de residência multiprofissional em saúde mental, propõe-se um Curso de Formação Pedagógica para os Programas de Residência Multiprofissional em Saúde Mental, visando melhorias na atuação pedagógica dos futuros enfermeiros especialistas que atuaram necessariamente como preceptores em saúde mental.

No primeiro momento, realizou-se uma pesquisa documental por compreender a riqueza de informações que se pode extrair e resgatar de documentos, o que também justifica o seu uso em várias áreas das Ciências Humanas e Sociais, possibilitando ampliar o entendimento de objetos cuja compreensão necessita de contextualização histórica e sociocultural.

$\mathrm{O}$ uso de documentos em pesquisa permite acrescentar a dimensão do tempo à compreensão do social. A análise documental favorece a observação do processo de maturação ou de evolução de indivíduos, grupos, conceitos, conhecimentos, comportamentos, mentalidades, práticas, entre outros ${ }^{6}$.

A avaliação constitui a primeira etapa de toda a análise documental que se aplica em cinco dimensões: (1) contexto, (2) autor, (3) autenticidade e confiabilidade, (4) natureza do texto, (5) conceitos-chave e a lógica interna do texto6.

O contexto é primordial em todas as etapas de uma análise documental que se avalie o contexto histórico no qual foi produzido o documento e o universo sócio-político do autor e daqueles a quem foi destinado, seja qual tenha sido a época em que o texto foi escrito.

Dessa forma, nossa primeira ação na direção de elaborar o produto foi contextualizar os cenários e condições em que foram propostos os projetos políticopedagógicos dos três cursos de especialização na 
modalidade Residência Multiprofissional em Saúde Mental em funcionamento na cidade do Rio de Janeiro. São eles: Programa de Residência Multiprofissional em Saúde Mental do Instituto Municipal Philippe Pinel da Secretaria Municipal de Saúde, Curso de Especialização Integrado em Saúde Mental na Modalidade de Residência Integrada e Multiprofissional em Saúde Mental da Universidade do Estado do Rio de Janeiro (UERJ) e Residência Multiprofissional em Saúde Mental no Instituto de Psiquiatria-IPUB da Universidade Federal do Rio de Janeiro (UFRJ).

Justifica-se a escolha desses três programas por serem os únicos programas desta natureza para a formação de enfermeiros especialistas na modalidade Residência Multiprofissional em Saúde Mental oferecidos no município do Rio de Janeiro. Para efeito de estudo, os documentos analisados foram: os programas políticos pedagógicos dos cursos, disciplinas oferecidas, ementas de disciplinas e carga horária teórica dos cursos.

A segunda ação empregada foi definir as formas de obtenção dos documentos. Foram estabelecidas as seguintes estratégias: busca nos sites das instituições; envio de e-mail aos coordenadores de programas de residência solicitando os projetos políticos pedagógicos dos cursos, nome das disciplinas oferecidas, ementas de disciplinas e carga horária teórica dos cursos; busca com egressos dos cursos.

Posteriormente, realizou-sea análise documental seguindo as seguintes etapas: (1) análise preliminar dos documentos, (2) análise dos dados-momento de reunir todas as partes - elementos da problemática ou do quadro teórico, contexto, autores, interesses, confiabilidade, natureza do texto, conceitos chave ${ }^{6}$.

$\mathrm{O}$ quarto passo foi proceder à análise dos materiais encontrados, comparou-se os programas políticos pedagógicos e construiu-se quadros comparativos entre os três programas estudados. Em seguida, os programas foram interpretados com base nas Diretrizes Nacionais sobre Residência e nos princípios da Reforma Psiquiátrica. Também foram considerados como parâmetro de análise consensos atuais de pesquisa encontrados na literatura dos 5 últimos anos sobre o ensino de saúde mental.

O quinto passo tratou de delinear a proposta de um módulo de ensino para capacitação pedagógica dos enfermeiros no âmbito dos Programas de Residência Multiprofissional em Saúde Mental.

Nesta etapa, com base na análise do contexto e considerando que os residentes em sua maioria já são profissionais, optou-se por adotar, no curso, uma perspectiva metodológica de ensino que valorizasse a experiência profissional do aluno, elegendo-se a aprendizagem significativa de Ausubel ${ }^{7}$. Para ele, a aprendizagem é construída e relacionada com os conhecimentos prévios, onde o sujeito adquire um papel ativo, reestruturando e organizando a informação. Ausubel, o conhecimento verdadeiro é construído pelo sujeito através de suas próprias interpretações, destinada a uma aplicação direta e sendo baseada na perspectiva de uma aprendizagem relacional, estando relacionada a conhecimentos prévios e experiências vividas. Um aspecto central desse tipo de aprendizagem é a relação cíclica existente entre nosso marco conceitual ou esquemas e a percepção da realidade material. Propôs os seguintes princípios que o ensino deveria seguir para conseguir uma aprendizagem significativa em seus alunos: ter em conta os conhecimentos prévios, proporcionar atividades que consigam despertar o interesse do aluno, criar um clima harmônico onde o aluno sinta confiança no professor, proporcionar atividades que permitam ao aluno opinar, trocar ideias e debater, explicar por meio de exemplos, guiar o processo cognitivo de aprendizagem e criar uma aprendizagem situada no ambiente sociocultural.

Finalmente desenvolveu-se o produto desse trabalho - um módulo de ensino teórico-prático sobre conhecimentos pedagógicos para os futuros enfermeiros especialistas em saúde mental baseado em situações-problemas vienciadas no âmbito da residência multiprofissional em saúde. Sugere-se que o módulo proposto, integre o programa do curso de residência multiprofissional e seja empregado no último semestre do curso de especialização.

\section{Implicações para a Prática}

$\mathrm{O}$ enfermeiro em sua prática muitas vezes realiza a função de preceptor sem ter recebido capacitação pedagógica específica para essa ação profissional. O presente estudo trata desse problema, trazendo contribuições para a elaboração de um módulo de ensino sobre capacitação pedagógica para o desempenho da preceptoria, a ser desenvolvido durante o curso de formação de residentes multiprofissionais em saúde mental.

\section{Considerações Finais}

O produto consistiu numa resposta a necessidade de capacitação dos preceptores de residência multiprofissional em saúde mental. Como o tempo de formação teórico na residência é restrito, precisa-se considerar uma formação pedagógica que possa ser potencializada na própria prática da residência. Assim, o produto proposto parte do princípio que o conhecimento precisa ser construído pelos próprios alunos, são eles os que, através de seu marco conceitual, devem interpretar a realidade material, contudo precisam ser orientados por professores/tutores com conhecimentos pedagógicos e conceituais suficientes para tornar seu processo de aprendizagem significativo, criativo e transformador. 


\section{Referências}

1. Brasil. Conselho Nacional de Saúde. Resolução no 287 de 08 de outubro de 1998.

2. Melo MCA et al. Perfil clínico e psicossocial dos moradores em hospitais psiquiátricos no estado do Ceará, Brasil. Ciência \& Saúde Coletiva. 2015; 20 (2): 343-352.

3. Amarante P. Loucos pela vida: a trajetória da reforma psiquiátrica no Brasil. Rio de Janeiro: SDE/ENSP, 2003.

4. Brasil. Resolução $\mathrm{N}^{0}$ 2, de 13 de Abril de 2012. Dispõe sobre Diretrizes Gerais para os Programas de Residência Multiprofissional e em Profissional de Saúde.

5. Peixoto LS. Saberes pedagógicos presentes na preceptoria da residência de enfermagem. 2016. Dissertação (Mestrado em Enfermagem) - Escola de Enfermagem Aurora de Afonso Costa, Universidade Federal Fluminense, Niterói.

6. Cellard A. A análise documental. In: Poupart J. et al. A pesquisa qualitativa: enfoques epistemológicos e metodológicos. Petrópolis: Vozes, 2008 .

7. Ausubel DP. Aquisição e retenção de conhecimentos: Uma perspectiva cognitiva. Lisboa. Editora Plátano. $1^{a}$ edição, 2003. 